\title{
Caste differentiation of spermatheca and organs related to sperm use and oviposition in the honeybee, Apis mellifera
}

\author{
Ayako $\mathrm{GoTOH}^{1}{ }^{1} \mathrm{Ken} \mathrm{SASAKI}^{2}$ \\ ${ }^{1}$ Department of Biology, Faculty of Science and Engineering and Institute for Integrative Neurobiology, Konan \\ University, 8-9-1 Okamoto, Higashinada-ku, Kobe 658-8501, Japan \\ ${ }^{2}$ Graduate School of Agriculture, Honeybee Science Research Center, Tamagawa University, Machida, Tokyo 194- \\ 8610, Japan
}

Received 26 March 2020 - Revised 20 August 2020 - Accepted 29 September 2020

\begin{abstract}
Striking queen-worker dimorphism associated with each task is a key feature of highly eusocial insects, including Apis mellifera. The present study histologically examined the developmental process of the internal reproductive organs including spermatheca, valve-fold in the vagina, semi-circular muscle surrounding the common oviduct, and abdominal ganglia in honeybee queens and workers. During the pupal stage, queens showed an increased spermathecal reservoir, development of the tracheal network surrounding the spermathecal reservoir, and elongation of the spermathecal gland. Compared with queens, these developmental processes were never observed during the pupal stage in workers. Moreover, development of the valve-fold and semi-circular muscle was aborted, and they became rudimentary at the middle pupal stage in workers. Morphological caste differences in the abdominal ganglia were observed from the prepupal stages, showing that the most posterior ganglion was fused with the anterior ganglia in queens but not in workers.
\end{abstract}

honeybee / caste differentiation / spermatheca / internal reproductive organs / morphogenesis

\section{INTRODUCTION}

Division of labor in reproduction is a crucial hallmark in eusocial insects. Prominent phenotypic differences between fertilized queens and sterile workers appear in honeybees and ants among eusocial Hymenoptera. Their queens show the highest fecundity, whereas worker reproduction is strictly regulated by the morphological and functional constraints of their reproductive organs (Michener 1974; Khila and Abouheif 2008, 2010).

Egg production is an important task of the reproductive caste, and ovariole numbers general-

Corresponding author: A. Gotoh, aya-got@konanu.ac.jp

Manuscript editor: David Tarpy ly reflect female fecundity. A. mellifera queens have more than 200 ovarioles and can lay 2000 eggs per day, up to a total of 1.5 million until they die (Snodgrass 1956). On the other hand, workers have a maximum of only a few dozen ovarioles, and their oviposition is restricted in response to the pheromonal control by the queen and brood. Despite only a small number of ovarioles in workers, their ovaries do not lose the ability to produce eggs, and they can plastically activate ovaries in the absence of the queen and brood within the colony.

In addition to the ovaries, caste dimorphism of other reproductive organs that are associated with sperm storage and usage is also crucial in social Hymenoptera. Reproductive females only mate at the beginning of their adult lives; therefore, they should store sufficient spermatozoa within the spermatheca to be used for fertilization throughout their 
long lifespan. The spermatheca of A. mellifera queens comprises a spermathecal reservoir, which is the sperm storage site and is covered by a developed tracheal network, a spermathecal duct, a pair of spermathecal glands, which is the secretory organ, and a sperm pump, which covers the spermathecal duct near the opening of the spermathecal reservoir (Snodgrass 1956; Dallai 1975). In social Hymenoptera, the ability to store sperm tends to be associated with the degree of sociality. In honeybees and ants, which show prominent caste dimorphism, the lifespan of the queen is longer, and the colony size is bigger than other social Hymenoptera; therefore, these queens store numerous spermatozoa in the spermathecal reservoir for long periods. For example, honeybee queens can store up to 4 million sperm cells within their spermatheca (Snodgrass 1956). Consequently, they require a huge spermathecal reservoir.

In contrast to queens, honeybee workers never mate, even in a queenless colony. In A. mellifera workers, the spermatheca is either absent or rudimentary (Snodgrass 1956; Gotoh et al. 2013). Histological analysis of the worker spermatheca revealed either a complete lack of or rudimental spermathecal gland, whereas the spermathecal ducts and the sperm pumps were found, and the spermathecal reservoir was lost (Gotoh et al. 2013). Worker virginity by degeneration of the spermatheca has also been observed in ants (Ito and Ohkawara 1994; Gobin et al. 2006) but not in other social Hymenoptera, such as bumblebees, stenogastrine wasps, polistine wasps, and vespine wasps (even vespine wasp workers never mate) (Schoeters and Billen 2000; Gotoh et al. 2008).

Queens show prominent development of an "oak leaf-shaped" structure known as a valve-fold, which is located on the ventral side of the lumen of the vagina, on the side opposite to the opening of the spermathecal duct (Fyg 1966). A few muscle fibers are attached to the ventral outer layer of the valvefold. In previous studies, the function of this organ was presumed to be as follows: (1) assist sperm migration into the spermathecal reservoir after mating and subsequently prevent of sperm loss by closing the genital chamber (Ruttner 1956), (2) arrest of spermatozoa to attach the eggs passed from the oviduct (Camargo and Mello 1970), and (3) arrest of the eggs to expose enough spermatozoa into the micropyle of the anterior side of the egg during fertilization (Sasaki and Obara 2002). However, the exact function remains somewhat unclear. Furthermore, developed semi-circular muscle fibers surrounding the common oviduct may produce a strong contractive force. The muscle fibers are considered to be important for oviposition since muscle contraction is hypothesized to induce egg transport from the common oviduct to the vagina as well as egg activation (Sasaki et al. 1997; Sasaki and Obara 2002). To the best our knowledge, no study has reported whether workers possess the valve-fold in the vagina and the semi-circular muscle surrounding the common oviduct.

The number of abdominal ganglia is reported to be different between castes in A. mellifera: Queens have four and workers have five abdominal ganglia (Ruttner 1961). In honeybee queens, the reproductive organs, such as the sperm pump, the spermathecal gland, the outer layer of the vaginal wall, the bursa copulatrix, the common oviduct, and the lateral oviduct, are thought to be innervated by nerves from the terminal abdominal ganglion (Ruttner 1961); these suggest that there are differences in the innervation system of reproductive organs and neural networks in the central nervous system for regulating the action of reproductive organs.

The reason why queens can produce a large amount of fertilized eggs, whereas workers can only occasionally produce unfertilized eggs although they have similar genetic backgrounds, is an area of research interest in highly eusocial Hymenoptera such as honeybees and ants. It is unclear how the distinct caste dimorphism of the reproductive organs is differentiated during the immature stages. In Apis mellifera, the caste is determined during the larval stage in response to nutrition. Thus, a caste-specific adult morphology is formed during the short period between the late larval and pupal stages. The developmental processes exhibiting ovary dimorphism between castes have been investigated in many previous studies (reviewed in Ronai et al. 2016); however, development of the reproductive organs related to sperm storage and usage have not been studied well, except in ants (Gotoh et al. 2009, 2016). Therefore, the present study examined the developmental process of the spermatheca, with a particular 
focus on the formation of the well-developed spermatheca in A. mellifera queens and degeneration of the spermatheca in workers. We also studied other organs related to reproduction, such as the vaginal valve-fold, semi-circular muscles in the common oviduct, and abdominal ganglia, and compared these organs between queens and workers.

\section{MATERIAL AND METHODS}

\subsection{Sample preparation}

Samples of immature and adult queens and workers were prepared using two respective queenright and queenless colonies of the European honeybee (Apis mellifera). Queen pupae and adults were reared by the Doolittle method with populous queenless colonies during the reproductive season in Japan (April to May). Worker pupae and adults were collected from the source queenright colonies. Pupal periods are 7 days in honeybee queens and 10 days in workers. We collected and examined 24 queens and 47 workers at various developmental stages from the prepupal to the adult stages, as previously described (Sasaki et al. 2018).

\subsection{Histological analysis}

Bee abdomens were fixed in ethanol:formalin:acetic acid $(16: 6: 1)$ or $4 \%$ paraformaldehyde and then dehydrated using a graded ethanol series, followed by clearing using xylene and embedding in paraffin. Longitudinal serial sections were cut to a thickness of $6 \mu \mathrm{m}$ and stained with hematoxylin and eosin. Sections were observed using a microscope (Olympus BX53), and images were captured using a digital camera (Olympus DP72).

\section{RESULTS}

\subsection{Spermatheca}

The spermathecal reservoir, the spermathecal gland, and the spermathecal duct were already differentiated at the prepupal stage in both castes (Figurela,m).

In queens, the size of the spermathecal reservoir dramatically increased, and the reservoir epithelial cells became thin until day one of the pupal stage (Figure 1a-b,gh). The reservoir then gradually enlarged, but its epithelial thickness did not change from the pupal stage (Figure $1 \mathrm{~b}-\mathrm{f}, \mathrm{h}-\mathrm{l}$ ). The spermathecal duct and the spermathecal gland discs also gradually elongated until the middle of the pupal stage (Figure $1 \mathrm{~b}-\mathrm{d}$ ). The trachea rudiment covering the spermathecal reservoir appeared during the prepupal stages (Figure $1 \mathrm{~g}-\mathrm{h}$ ); it conspicuously developed from day two of the pupal stage, with establishment of a thick tracheal network at day three of the pupal stage (Figure 1i-1). The sperm pump rudiment appeared surrounding the spermathecal duct near the spermathecal reservoir on the first day of the pupal stage.

In workers, the spermathecal rudiment showed a hook-like morphology until day one of the pupal stage. As the spermathecal gland was attached at the boundary between the duct-shaped structure and apical side of the hook structure, the apical side of the hook structure was considered to be the spermathecal reservoir rudiment (Figure 1mn). The spermathecal reservoir rudiment-like structure degenerated at days two to three of the pupal stage, and a rod-shaped spermatheca was formed (Figure 1o-r). The spermathecal duct and the spermathecal gland did not elongate like that of the queens (Figure $1 \mathrm{~b}-\mathrm{d}, \mathrm{n}-\mathrm{p}$ ). The muscle fibers around the apical side of the spermathecal discs started to develop from days two to three of the pupal stage (Figure 1o); this tissue may be homologous with that of the sperm pump. The tracheal network surrounding the spermatheca did not develop during the pupal stage.

\subsection{Valve-fold in the vagina and semi- circular muscle surrounding the com- mon oviduct}

In queens, the valve-fold structure began to appear at the beginning of the pupal stage (Figure 2a), and a rod-like structure formed at day two of the pupal stage (Figure 2b). The valve-fold structure seen in the adult stage was 
formed by day three of the pupal stage (Figure 2ce). Semi-circular muscle fibers were already developed on day one of the pupal stage (Figure 2ae).

In workers, a valve-fold-like structure began to appear soon after pupation (Figure 2f, arrow); however, it did not form the shape of the queen valve-fold structures, and it soon reduced in size (Figure $2 \mathrm{~g}-\mathrm{j}$, arrow). The muscular fibers attached to the ventral outer layer of the valve-fold did not develop. Semi-circular muscle fibers developed until day three of the pupal stage (Figure $2 \mathrm{f}-\mathrm{g}$ ), but these gradually diminished with age (Figure $2 \mathrm{~h}-\mathrm{j}$ ).

\subsection{Abdominal ganglia}

In queens, the three posterior ganglia were fused at the prepupal stage (Figure 3a) and were elongated (Figure $3 b-c$ ); they finally became close and compact (Figure 3d-e), resulting in the formation of the fourth abdominal ganglion in the adult stage (Figure 3f). In workers, the three posterior ganglia were separated from each other at the prepupal stage (Figure 3g), but then the two anterior ganglia became fused at the pupal stage (Figure $3 \mathrm{~h}-\mathrm{k}$ ); thus, the fourth adult abdominal ganglion was formed (Figure 31). The most posterior ganglion, which became the fifth adult abdominal ganglion, was continually separated from the anterior ganglia by the adult stage (Figure $3 g-1$ ).

\section{DISCUSSION}

The spermathecal reservoir is huge in A. mellifera in comparison with those of related bee species (Pabalan et al. 1996; Schoeters and Billen 2000; Gotoh unpubl. data). As it is also huge in ant queens (Gotoh et al. 2008; Gotoh unpubl. data), the evolution of the enormous spermatheca in queens is commonly important for the prominent reproductive ability of these highly eusocial hymenopteran species. The developmental processes of the spermatheca in reproductive females have been reported in ants and polistine wasps (Gotoh et al. 2009). In these species, formation of the spermathecal reservoir mainly occurs during the pupal stages. In ant queens, morphological changes in the reservoir distal epithelial cells from cuboidal to squamous, resulting in an increased cell surface, occur in a short period from mid- to late pupal stage. This specialized process is never observed in polistine females, whose spermatheca reservoir size is not huge; therefore, this process is necessary for the formation of the large spermathecal reservoir in ant queens (Gotoh et al. 2009). In honeybee queens, however, the size of the spermathecal reservoir is already dramatically enlarged from the prepupal stage to the beginning of the pupal stage; it then gradually increases in size during the pupal stage. As the epithelial cells of the spermathecal reservoir become thin, the stretching of the cell shape may cause a significant increase in reservoir size, in addition to cell proliferation, until the beginning of the pupal stage. Moreover, the shape of the cuboidal epithelium of the reservoir never changes during the pupal stage, suggesting that proliferation of epithelial cells without the morphological change may be the primary mechanism underlying the increase in reservoir size, given the final reservoir size. Thus, although the huge spermathecal reservoir is a common feature in honeybee and ant queens, it has apparently evolved independently in a very different manner in each lineage to maximize the sperm cell storage capacity.

A columnar epithelium has been observed in the spermathecal reservoir of social Hymenoptera, such as bumblebees, honeybees, ants, and polistine and vespine wasps, and is believed to be important for sperm storage by transporting metabolites outside and inside the reservoir (Dallai 1975; Wheeler and Krutzsch 1994; Schoeters and Billen 2000; Gotoh et al. 2008). In ants and polistine wasps, the epithelial thickness doubles, resulting in the formation of the columnar epithelium at the end of the pupal stage (Gotoh et al. 2009); however, the epithelium does not become thick until emergence in A. mellifera . Poole (1970) previously reported that the shape of the epithelial cells changes from a cuboidal to columnar, with age and mating status; indeed, the average thicknesses of the epithelium in 6- to 12-month-old mated queens is twice that of newly emerged virgin queens. In some ant species, an increase in hilar epithelium thickness after eclosion or mating has been observed (Allard et al. 


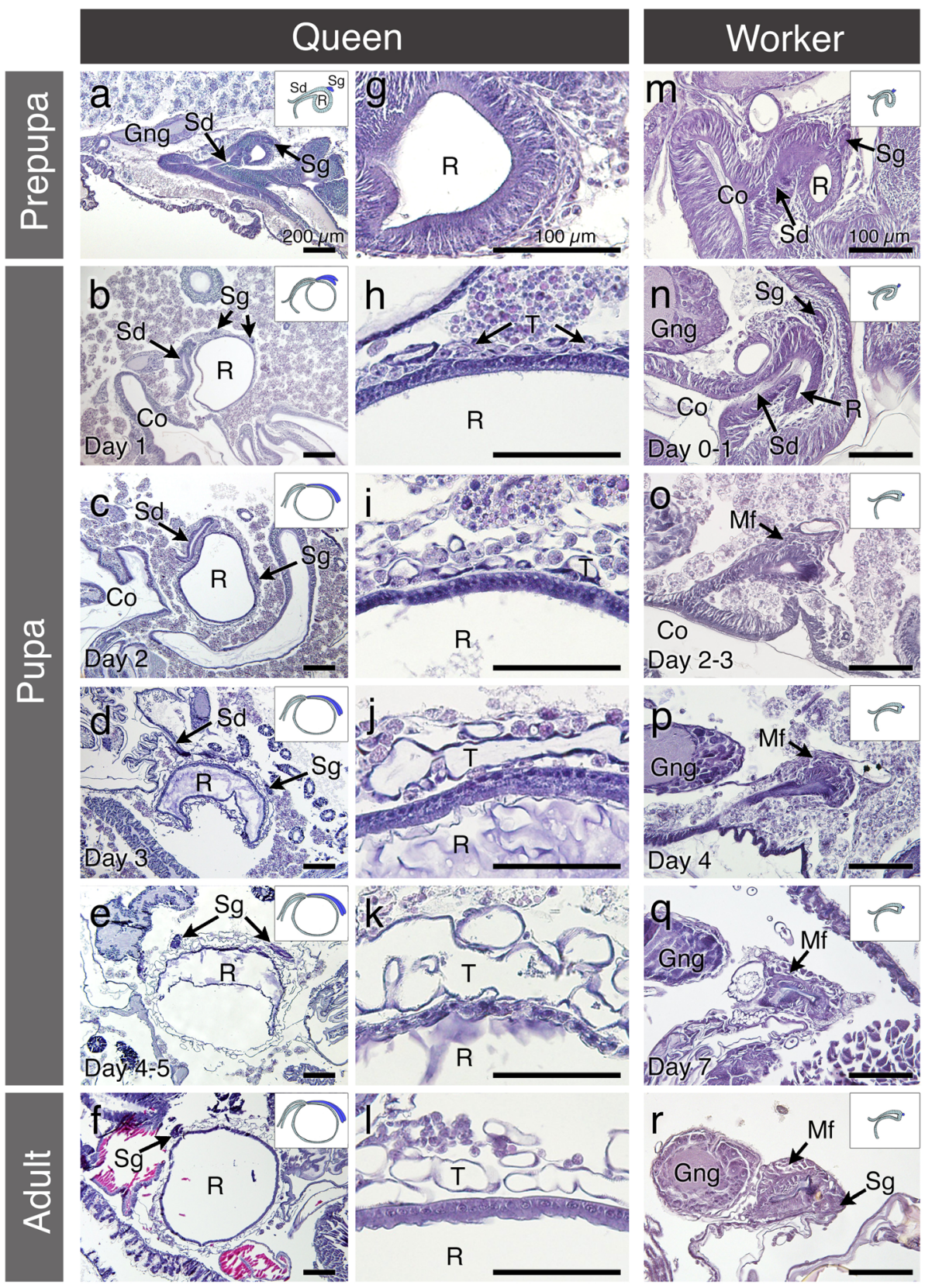

Figure 1. Developmental process of the spermatheca in queens (a-l), showing a magnified view of part of the spermathecal reservoir epithelium $(\mathbf{g}-\mathbf{l})$ and workers $(\mathbf{m}-\mathbf{r})$. Schematic illustration of the spermatheca reservoir, the spermathecal gland, and the spermathecal duct are shown in upper right corner of $(\mathbf{a}-\mathbf{f})$ and $(\mathbf{m}-\mathbf{r})$. Co, common oviduct; Gng, ganglion; R, reservoir; Mf, muscle fibers; Sd, spermathecal duct; Sg, spermathecal gland; T, trachea. Scale bars represent $200 \mu \mathrm{m}(\mathbf{a}-\mathbf{f})$ and $100 \mu \mathrm{m}(\mathbf{g}-\mathbf{r})$.

2005; Gotoh unpublished data). However, the biological significance of the delay in developmental timing remains unclear since their reproductive biology, such as mating system, mating frequency, and sperm storage period, lack coherence among these species. 


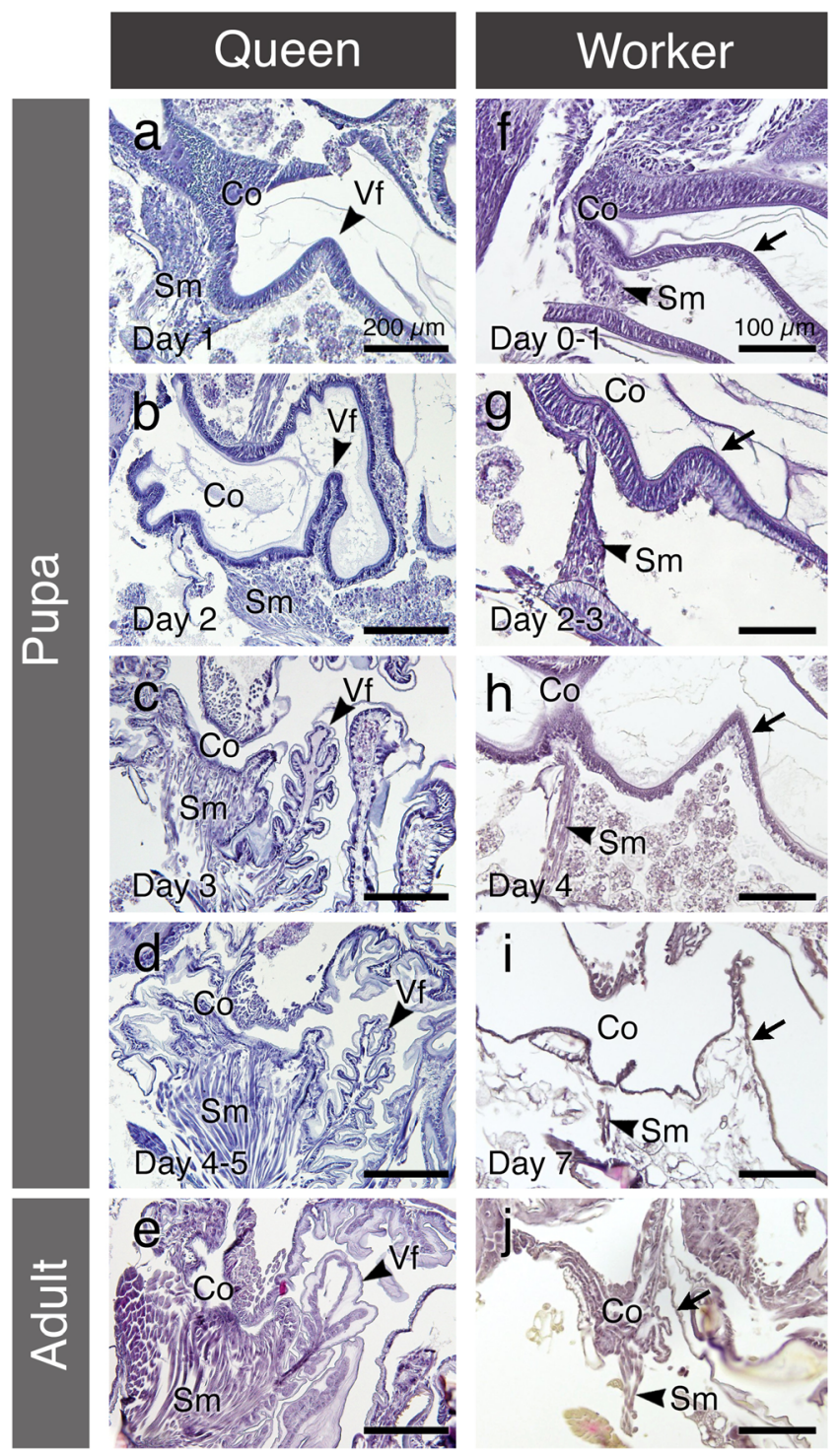

Figure 2. Developmental process of the valve-fold in the vagina and the semi-circular muscle surrounding the common oviduct in queens and workers. Co, common oviduct; Sm, semi-circular muscle; Vf, valve-fold. Arrows indicate valve-fold-like structure in workers. Scale bars represent $200 \mu \mathrm{m}(\mathbf{a}-\mathbf{e})$ and $100 \mu \mathrm{m}(\mathbf{f}-\mathbf{j})$.

In workers, the morphology of the spermathecal disc during the prepupal stage was homologous to that of queens, although it was small. This indicates that the developmental process of the spermatheca progressed until the prepupal stages; however, the later processes that were observed in the spermatheca morphogenesis of honeybee queens, namely, the enlargement of the spermatheca reservoir, development of the tracheal network surrounding the reservoir, and elongation of the spermathecal duct and of the spermathecal glands, were arrested in workers. This developmental pattern is similar as that of vestigial spermatheca formation in the workers of some ant species, in which the process of increased spermathecal reservoir size is aborted (Gotoh et al. 2016). These suggest that the developmental processes associated with cell 


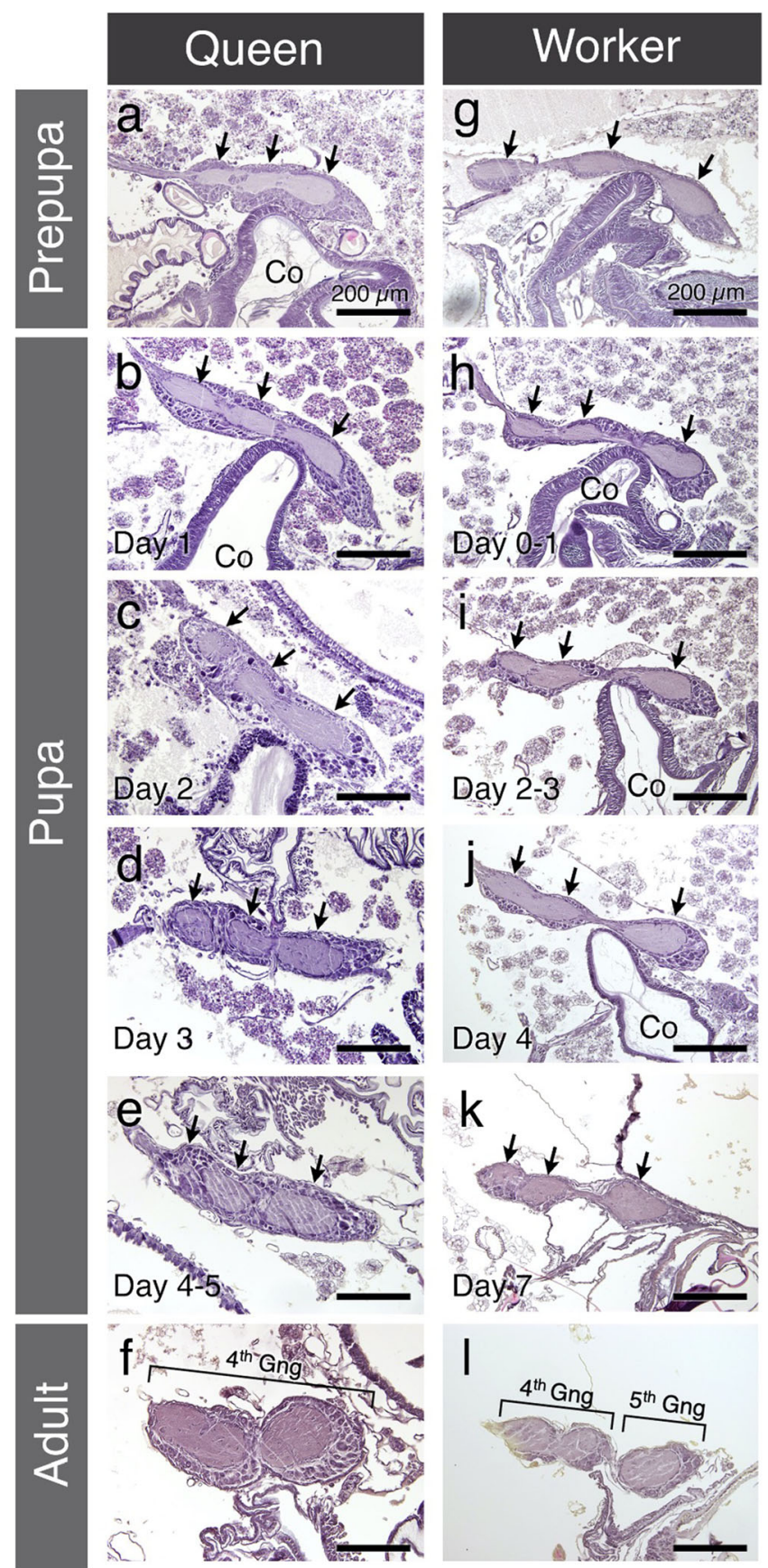

Figure 3. Developmental process of the posterior abdominal ganglia in queens and workers. Co, common oviduct; Gng, ganglion. Arrows indicate the three posterior ganglia derived from the larval stage. Scale bars represent $200 \mu \mathrm{m}$.

proliferation and alteration of cellular morphology are likely to be canceled in the spermatheca morphogenesis of workers in each lineage, probably caused by high developmental cost. Subsequently, the spermathecal reservoir disc disappeared in A. mellifera, whereas it has been 
reported that the spermathecal reservoir disc does not disappear and becomes vestigial or all spermathecal discs completely degenerates in ant species (Gotoh et al. 2016). This indicates that the developmental modification process bringing the morphological virginity in worker caste evolved in a different way between honeybees and ants.

Possible functions of the valve-fold have been discussed (see Introduction). In workers, development of the valve-fold structure was aborted and became vestigial; therefore, we suggest that this structure plays a role in sperm storage or use but not in oviposition in queens since workers never mate but can oviposit.

In workers, the semi-circular muscle also developed until the early pupal stages, similar to development in queens; however, this muscle dramatically degenerated from the middle of the pupal stage and became vestigial. This structure is believed to be related to egg transport or egg activation during oviposition (Sasaki et al. 1997; Sasaki and Obara 2002). If this hypothesis is correct, the muscle layers may develop after the ovaries are activated in a queenless colony, or the muscular volume may be sufficient because of the oviposition rate that is far lower in workers than in queens.

In holometabolous insects, larval ganglia are reorganized into adult ganglia at metamorphosis (Pinto et al. 2003; Chapman et al. 2013). In honeybee workers, the number of the abdominal ganglia is eight at the larval stage; however, it reduces to five by the adult stage, resulting from the fusion of the ganglia during the pupal stage (Snodgrass 1956). We revealed that the number of abdominal ganglia in adult queens and workers is determined depending on whether the most posterior ganglion fuses with the anterior ganglia during the pupal stage. In A. mellifera queens, the reproductive organs are thought to be innervated by nerves from the terminal abdominal ganglion (Ruttner 1961). Control of the sperm pump contraction is, for instance, believed to play a role in regulation of sperm release from the spermathecal reservoir for fertilization as well as sperm uptake soon after mating (Bresslau 1905; Ruttner and Koeniger 1971; Baer et al. 2016). In social
Hymenoptera, regulation of sperm ejection is crucial for sperm economy, because reproductive females never remate after colony founding or succession, and the control of colony sex ratio, due to their haplodiploidy sex determination system (den Boer et al. 2009; Baer et al. 2016). The caste difference of the terminal ganglia development already occurs at the prepupal stage, suggesting that early establishment of the caste-specific neural network may be important for distinct reproductive division of labor in honeybees.

Apoptosis-driven morphogenesis is widely common in animals. This system is also coopted to form worker-specific morphologies caused by the degeneration of ovaries in bees (Hartfelder and Steinbrück 1997; Boleli et al. 1999; Ronai et al. 2015, 2017) and elimination of wing discs in ants (Sameshima et al. 2004; Gotoh et al. 2005). In the stingless bee Melipona quadrifasciata, apoptotic cell death has been associated with the fusion of the ventral ganglia from the larval to pupal stages because apoptotic signals have been detected in the merged region of the fused ganglia (Pinto et al. 2003). Therefore, caste differences in adult ganglia formation may also be associated with apoptosis. In the present study, it was difficult to detect apoptosis in the small vestigial reproductive organs of workers and ganglia in both castes; therefore, apoptosis should be investigated in future studies.

This is the first comparative study on the processes involved in the development of internal reproductive organs, other than the ovaries, in A. mellifera queens and workers. In addition to specialization of queen morphology to increase reproductive ability, the evolution of the modification systems in worker reproductive organs is a remarkable innovation for highly eusocial species (Ronai et al. 2016), because it promotes strict reproductive division of labor, leading to low reproductive conflict within a colony (Bourke 1999). Our histological findings of the spermatheca, valve-fold, semicircular muscle, and abdominal ganglia, which are related to reproductive functions, can be used in conjunction with molecular mechanisms to provide a comprehensive understanding of caste dimorphisms. 


\section{AUTHORS' CONTRIBUTIONS}

$\mathrm{AG}$ and $\mathrm{KS}$ designed the experiments. KS prepared honeybee samples. AG conducted the histological analysis. AG and KS wrote the manuscript.

\section{FUNDING}

This study was supported by Tomizawa Jun-ichi \& Keiko Fund of Molecular Biology Society of Japan for Young Scientist to A.G. and JSPS KAKENHI grant number JP17K07491 to K.S.

Différenciation des spermathèques et des organes d'utilisation du sperme et du frai chez l'abeille domestique, Apis mellifera.

abeille mellifère / différenciation des castes / spermathèque / organes reproducteurs internes / morphogenèse.

Die Kastendifferenzierung der Spermatheka und von Organen der Spermanutzung und Eiablage in der Honigbiene, Apis mellifera.

Honigbiene / Kastendifferenzierung/ Spermatheka / innere Reproduktonsorgane / Morphogenese.

\section{REFERENCES}

Allard, D., Ito, F., Gobin, B., Tsuji, K., Billen, J. (2005) Differentiation of the reproductive tract between dominant and subordinate workers in the Japanese queenless ant Diacamma sp.. Acta Zool. 86, 159-166.

Baer, B., Collins, J., Maalaps, K., den Boer, S.P.A. (2016) Sperm use economy of honeybee (Apis mellifera) queens. Ecol. Evol. 6, 2877-2885.

Boleli, I.C., Paulino-Simões, Z.L., Gentile Bitondi, M.M. (1999) Cell death in ovarioles causes permanent sterility in Frieseomelitta varia worker bees. J. Morphol. 242, 271-282.

Bourke, A.F.G. (1999) Colony size, social complexity and reproductive conflict in social insects. J. Evol. Biol. 12, 245-257.

Bresslau, E. (1905) Der Samenblasengang der Bienekönigin (Studien über den Geschlechtsapparat und die Fortpflanzung der Bienen. I.). Zool. Anz., 29, 299-323.

Camargo, J.M.F., Mello, M.L.S. (1970) Anatomy and histology of the genital tract, spermatheca, spermathecal duct and glands of Apis mellifera queens (Hymenoptera: Apidae). Apidologie 1, 351-373.

Chapman, R. F., Simpson, S. J., Douglas, A. (2013) The insects: structure and function. Cambridge Univ. Press, Cambridge.

Dallai, R. (1975) Fine structure of the spermatheca of Apis mellifera. J. Insect Physiol. 21, 89-109.

den Boer, S.P.A., Baer, B., Dreier, S., Aron, S., Nash, D.R., Boomsma, J.J. (2009) Prudent sperm use by leaf-cutter ant queens. Proc. Biol. Sci. 276, 3945-3953.

Fyg, W. (1966) Über den Bau und die Funktion der Valvula Vaginalis der Bienenkönigin (Apis mellifica L.). Z. Bienenforsch. 8, 256-266.

Gobin, B., Ito, F., Peeters, C., Billen, J. (2006) Queenworker differences in spermatheca reservoir of phylogenetically basal ants. Cell Tissue Res. 326, 169-178.

Gotoh, A., Billen, J., Hashim, R., Ito, F. (2008) Comparison of spermatheca morphology between reproductive and non-reproductive females in social wasps. Arthropod Struct. Dev. 37, 199-209.

Gotoh, A., Billen, J., Hashim, R., Ito, F. (2009) Evolution of specialized spermatheca morphology in ant queens: insight from comparative developmental biology between ants and polistine wasps. Arthropod Struct. Dev. 38, 521-525.

Gotoh, A., Billen, J., Hashim, R., Ito, F. (2016). Degeneration patterns of the worker spermatheca during morphogenesis in ants (Hymenoptera: Formicidae). Evolution and Development, 18, 96-104.

Gotoh, A., Ito, F., Billen, J. (2013) Vestigial spermatheca morphology in honeybee workers, Apis cerana and Apis mellifera from Japan. Apidologie 44, 133-143.

Gotoh, A., Sameshima, S., Tsuji K, Matsumoto, T., Miura, T. (2005) Apoptotic wing degeneration and formation of an altruism-regulating glandular appendage (gemma) in the ponerine ant Diacamma sp. from Japan (Hymenoptera, Formicidae, Ponerinae). Dev. Genes Evol. 215, 69-77.

Hartfelder, K., Steinbrück, G. (1997) Germ cell cluster formation and cell death are alternatives in castespecific differentiation of the larval honey bee ovary. Invertebr. Reprod. Dev. 31, 237-250.

Ito, F., Ohkawara, K. (1994) Spermatheca size differentiation between queens and workers in primitive ants: Relationship with reproductive structure of colonies. Naturwissenschaften 81, 138-140.

Khila, A., Abouheif, E. (2008) Reproductive constraint is a developmental mechanism that maintains social harmony in advanced ant societies. Proc. Natl. Acad. Sci. USA. 105, 17884-17889.

Khila, A., Abouheif, E. (2010) Evaluating the role of reproductive constraints in ant social evolution. Philos. Trans. R. Soc. Lond. B Biol. Sci. 365, 617-630.

Michener, C.D. (1974) The social behavior of the bees: A comparative study. Belknap Harvard University Press, Cambridge.

Pabalan, N., Davey, K.G. and Packer, L. (1996) Comparative morphology of spermathecae in solitary and 
primitively eusocial bees (Hymenoptera; Apoidae). Can. J. Zool. 74, 802-808.

Pinto, L. Z., Laure, M.A.F.B., Bitondi, M.M.G., Hartfelder, K., Simões, Z.L.P. (2003). Ventral nerve cord remodeling in a stingless bee (Melipona quadrifasciata anthidioides, Hymenoptera, Apidae) depends on ecdysteroid fluctuation and programmed cell death. Int. J. Dev. Biol. 47, 385-388.

Poole, H.K. (1970) The wall structure of the honey bees spermatheca with comments about its function. Ann. Entomol. Soc. Am. 63, 1625-1628.

Ronai, I., Barton, D.A., Oldroyd, B.P., Vergoz, V. (2015). Regulation of oogenesis in honey bee workers via programed cell death. J. Insect Physiol. 81, 36-41.

Ronai, I., Vergoz, V., Oldroyd, B.P. (2016). The Mechanistic, Genetic, and Evolutionary Basis of Worker Sterility in the Social Hymenoptera. Advances in the Study of Behavior (Vol. 48). Elsevier Ltd.

Ronai, I., Vergoz, V., Oldroyd, B.P., Allsopp, M.H., Tan, K., Dong, S., Liu, X. (2017). The dynamic association between ovariole loss and sterility in adult honeybee workers. Proc. R. Soc. B 284, 20162693.

Ruttner, F. (1956). Zur Frage der Spermaübertrangung bei der Bienenkönigin. Insect. Soc. 3, 351-359.

Ruttner, F. (1961). Die Innervation der Fortpflanzungsorgane der Honigbiene (Apis mellifica L.). Z. Bienenforsch. 5, 253-266.

Ruttner, F., Koeniger, G. (1971) Die Füllung der Spermatheka der Bienenkönigin. Z. vergl. Physiologie $72,411-422$.
Sameshima, S, Miura, T., Matsumoto, T. (2004) Wing disc development during caste differentiation in the ant Pheidole megacephala (Hymenoptera: Formicidae). Evol. Dev. 6, 336-341.

Sasaki, K., Obara, Y. (2002). Egg activation and timing of sperm acceptance by an egg in honeybees (Apis mellifera L.), Insect. Soc. 49, 234-240.

Sasaki, K., Sobajima, H., Satoh, T., Obara, Y. (1997). Activation in vitro of unfertilized egg development in honeybee queens. Naturwissenschaften 84, 74-76.

Sasaki, K., Ugajin, A., Harano, K.I. (2018). Caste-specific development of the dopaminergic system during metamorphosis in female honey bees. PLoS ONE 13, e0206624.

Schoeters, E., Billen, J. (2000) The importance of the spermathecal duct in bumblebees. J. Insect Physiol. 46, 1303-1312.

Snodgrass, R.F. (1956) The Anatomy of Honey Bee. Comstock Publ. Assoc. Cornell. Univ. Press, Ithaca.

Wheeler, D.E., Krutzsch, P.H. (1994) Ultrastructure of the spermatheca and its associated gland in the ant Crematogaster opuntiae (Hymenoptera, Formicidae). Zoomorphology 114, 203-212.

Publisher's note Springer Nature remains neutral with regard to jurisdictional claims in published maps and institutional affiliations. 